\title{
Elaboração de Vídeos Médicos Educacionais para Treinamento de Habilidades de Estudantes do Curso de Medicina
}

\section{Preparation of Educational Videos for Skills Training for Medical Students in Medical School}

Felipe Teles Arruda

Allan Danek

Karen Cristine Abrão

Ana Paula Quilici ${ }^{I}$

\section{PALAVRAS-CHAVE}

- Educação Médica.

- Filmes e Vídeos Educativos.

- Simulação.

- Estudantes de Medicina.

KEYWORDS

- Medical Education.

- Instructional Films and Videos.

- Simulation.

- Medical Students.
Recebido em: 26/06/2012

Reencaminhado em: 03/07/2012

Aprovado em: $12 / 07 / 2012$

\section{RESUMO}

A simulação proporciona um ambiente de aprendizado seguro e controlado para o treinamento e o desenvolvimento de habilidades médicas essenciais, compatíveis com o que se espera na formação dos profissionais necessários para atender as demandas modernas da saúde. Este artigo relata uma experiência de desenvolvimento, por estudantes de Medicina, de vídeos educacionais para o ensino de habilidades relacionadas à semiologia e a procedimentos médicos, visando aprimorar o aprendizado e fortalecer o embasamento teórico e prático destas habilidades.

\section{ABSTRACT}

The simulation provides a safe and monitored learning environment for training and development of basic medical skills, consistent with what is expected in the training necessary to meet the demands of modern health. This article reports an experience of developing, by medical students, educational videos for teaching skills related to semiology and medical procedures in order to improve learning and strengthen the basis of these theoretical and practical skills. 


\section{INTRODUÇÃO}

A exposição precoce dos estudantes de Medicina aos procedimentos e competências da profissão facilita e dá sentido ao aprendizado. A introdução de novas tecnologias e métodos de ensino tem contribuído para aprimorar e permitir este aprendizado de maneira mais precoce, garantindo a segurança dos pacientes. Uma destas novas metodologias é a Simulação Médica, que, além de permitir a exposição repetida segura, expõe estudantes a inúmeras situações da prática profissional e contribui para aperfeiçoar habilidades não técnicas, tais como comunicação e trabalho em equipe, colaboração, envolvimento e tomada de decisão ${ }^{1-2}$.

Uma das ferramentas que facilita o aprendizado de habilidades técnicas é o checklist ou guia, instrumento que decompõe o procedimento a ser aprendido em várias etapas, orientando passo a passo as ações a serem executadas em ordem cronológica para completar tal procedimento. Estes instrumentos são criados pelos professores ou extraídos de tratados médicos e podem ser utilizados tanto em aulas práticas com supervisão docente quanto no estudo individual dos alunos. O Quadro 1 mostra um exemplo de checklist.

\section{QUADRO 1}

Checklist de coleta do Papanicolaou.

(as colunas à direita indicam a execução correta da etapa descrita)

PROCEDIMENTO: Coleta da colpocitologia oncótica HABILIDADE: Realizar a coleta da colpocitologia oncótica (exame de Papanicolaou)

\begin{tabular}{|l|c|c|}
\hline SEQUÊNCIA DE AÇÕES & \multicolumn{2}{|l|}{ CHECAGEM } \\
\hline $\begin{array}{l}\text { A paciente deverá esvaziar previamente a bexiga e não deverá } \\
\text { estar menstruada ou ter tido relações sexuais nas últimas 48 } \\
\text { horas }\end{array}$ & ( ) Sim & ( ) Não \\
\hline 1. Lave as mãos. & ( ) Sim & ( ) Não \\
\hline $\begin{array}{l}\text { 2. Assegure-se da privacidade durante a realização do } \\
\text { exame e solicite a presença de um acompanhante. }\end{array}$ & ( ) Sim & ( ) Não \\
\hline $\begin{array}{l}\text { 3. Explique o procedimento à paciente. } \\
\text { 4. Posicione a paciente para a realização do exame em } \\
\text { mesa ginecológica, com perneiras, garantindo a boa } \\
\text { exposição da genitália e o conforto da paciente. }\end{array}$ & ( ) Sim & ( ) Não \\
\hline $\begin{array}{l}\text { 5. Cubra a paciente. } \\
\text { 6. Prepare o material a ser utilizado. }\end{array}$ & ( ) Sim & ( ) Não \\
\hline $\begin{array}{l}\text { 7. Identifique o frasco com o nome da paciente, idade e } \\
\text { data da última menstruação. Identifique a lâmina com } \\
\text { o nome da paciente na extremidade fosca. }\end{array}$ & ( ) Sim & ( ) Não \\
\hline 8. Calce luvas. & ( ) Sim & ( ) Não \\
\hline $\begin{array}{l}\text { 9. Lubrifique o espéculo com água ou com pequena } \\
\text { quantidade de lubrificante (para não prejudicar a } \\
\text { avaliação citológica). }\end{array}$ & ( ) Sim & ( ) Não \\
\hline \begin{tabular}{l} 
10. Sente-se em frente à paciente e ajuste a iluminação. \\
\hline
\end{tabular} & ( ) Sim & ( ) Não \\
\hline
\end{tabular}

\begin{tabular}{|c|c|c|}
\hline $\begin{array}{l}\text { 11. Inicie o EXAME ESPECULAR. Mantenha os } \\
\text { grandes lábios afastados com a mão não dominante. } \\
\text { Com a mão dominante, insira o } \\
\text { espéculo no introito vaginal, fechado e com o maior } \\
\text { eixo no sentido longitudinal e inclinado } \\
\text { aproximadamente } 30 \text { graus. }\end{array}$ & ( ) Sim & ( ) Não \\
\hline $\begin{array}{l}\text { 12. Rode o espéculo delicadamente para que o maior } \\
\text { eixo fique no sentido horizontal e abra as lâminas. } \\
\text { Utilize a mão esquerda para apoiar o espéculo e a } \\
\text { direita para abrir a válvula. }\end{array}$ & ( ) Sim & ( ) Não \\
\hline $\begin{array}{l}\text { 13. Manipule delicadamente o espéculo até identificar } \\
\text { o colo uterino, o orifício cervical externo e a junção } \\
\text { escamo-colunar. }\end{array}$ & ( ) Sim & ( ) Não \\
\hline $\begin{array}{l}\text { 14. Ajuste a porção chanfrada a espátula de Ayres no } \\
\text { orifício cervical externo e raspe levemente o colo e } \\
\text { entrada do canal endocervical rodando } 360 \text { graus. A } \\
\text { porção mais longa da chanfradura deve ficar dentro do } \\
\text { orifício cervical. }\end{array}$ & ( ) Sim & ( ) Não \\
\hline $\begin{array}{l}\text { 15- Com a porção ovalada da espátula de Ayres, raspe } \\
\text { o fundo de saco vaginal. }\end{array}$ & ( ) Sim & ( ) Não \\
\hline $\begin{array}{l}\text { 16- Espalhe o material das duas extremidades da } \\
\text { espátula delicadamente na lâmina de vidro. Divida a } \\
\text { lâmina em } 3 \text { terços, } 1 / 3 \text { para o material da junção } \\
\text { escamo-colunar, } 1 / 3 \text { para o fundo vaginal e um para o } \\
\text { canal endocervical. Não espalhe material na } \\
\text { extremidade fosca da lâmina. }\end{array}$ & ( ) Sim & ( ) Não \\
\hline $\begin{array}{l}\text { 17- Insira a escovinha cervical no canal endocervical e } \\
\text { gire } 360 \text { graus. }\end{array}$ & ( ) Sim & ( ) Não \\
\hline $\begin{array}{l}\text { 18. Espalhe o material da escovinha no último } 1 / 3 \text { da } \\
\text { lâmina de vidro, rodando a escova sobre ela. }\end{array}$ & ( ) Sim & ( ) Não \\
\hline $\begin{array}{l}\text { 19. Retire o espéculo vaginal fechando as lâminas } \\
\text { delicadamente e o descarte. }\end{array}$ & ( ) Sim & ( ) Não \\
\hline $\begin{array}{l}\text { 20. Fixe a lâmina com spray fixador, mantendo } \\
\text { distância do jato de pelo menos } 20 \mathrm{~cm} \text { da lâmina para } \\
\text { evitar perda de material (alternativa: inserir a lâmina } \\
\text { em frasco com álcool 95\%). }\end{array}$ & ( ) Sim & ( ) Não \\
\hline 21. Retire as luvas e descarte. & ( ) $\operatorname{Sim}$ & ( ) Não \\
\hline aça anotações dos ach & ( ) $\mathrm{Sim}$ & () Não \\
\hline 23- Explique eventuais achados à paciente. & () $\operatorname{Sim}$ & ( ) Não \\
\hline \multicolumn{3}{|l|}{$\begin{array}{l}\text { Material necessário } \\
\text { - Mesa ginecológica; } \\
\text { - Avental de pano higienizado ou descartável para a paciente; } \\
\text { - Lençol para cobrir a paciente; } \\
\text { - Foco para iluminação; } \\
\text { - Luvas de procedimento (não estéreis); } \\
\text { - Espéculo vaginal; } \\
\text { - Lubrificante ou água; } \\
\text { - Espátula de Ayres; } \\
\text { - Escova cervical; } \\
\text { - Lâmina de vidro; } \\
\text { - Recipiente para acondicionamento da lâmina; } \\
\text { - Material para identificação da paciente; } \\
\text { - Fixador spray ou frasco com álcool 95\%. }\end{array}$} \\
\hline
\end{tabular}

Fonte: Bates, B. Bates' Guide to Physical Examination \& History Taking. Lippincott Williams \& Wilkins; 8th Edition, 2002.

Numa perspectiva pedagógica, a teoria de Mayer de aprendizagem multimídia postula que as pessoas aprendem melhor quando as imagens são combinadas com palavras em um ambiente de aprendizagem eletrônica ${ }^{3}$. A definição de Mayer de multimídia inclui animação e narração, não apenas 
texto correspondente e ilustrações estáticas. Os estudos desse autor, que envolvem o uso de tutoriais multimídia curtos, mostraram significativos resultados de aprendizagem e constituíram o marco conceitual para o presente projeto.

Além disso, alguns estudos mostraram que os vídeos tutoriais são materiais educacionais convenientes e que aumentam a motivação e satisfação dos alunos com o processo de ensino-aprendizagem ${ }^{4-5}$.

Portanto, acredita-se que a combinação entre o checklist e vídeos tutoriais pode incrementar o aprendizado das habilidades médicas num ambiente de simulação. Com base nestes conceitos, o presente projeto foi proposto por dois estudantes do quarto e oitavo semestres do curso de Medicina, com o objetivo de facilitar o estudo individualizado dos alunos, padronizar os procedimentos e aumentar a segurança e motivação dos estudantes que estão sendo introduzidos à Semiologia Médica do primeiro ao quinto semestre do curso ${ }^{6-7}$.

\section{RELATO DA EXPERIÊNCIA}

O presente projeto foi realizado por dois estudantes do quarto e oitavo períodos do curso de Medicina. Os vídeos foram produzidos no laboratório de Simulação em Saúde da própria universidade, utilizando equipamentos médicos reais e/ou simulados, manequins que mimetizam funções vitais humanas, e os próprios autores representaram pacientes na execução de algumas técnicas semiológicas.

Para a filmagem, foi empregada uma filmadora digital DCR-SR45 Sony com tripé, e a edição foi feita em um computador pessoal com uso dos softwares After effects CS5, Photoshop CS5 e Corel VideoStudio Pro X4. Tanto a filmagem quanto a edição dos vídeos foram executadas pelos alunos autores do projeto.

Inicialmente, foram feitas reuniões para a escolha dos procedimentos para as futuras gravações e possíveis correções dos instrumentos, feitas junto aos professores orientadores. Os temas foram escolhidos pela pertinência para alunos que estão em fase de aprendizado de Semiologia e procedimentos médicos. Os vídeos escolhidos até o presente momento estão listados no Quadro 2.

Uma vez definidos os procedimentos, foram separados os respectivos checklists e identificados os equipamentos e recursos necessários à confecção dos vídeos. Diversas gravações foram testadas para avaliação do melhor ângulo e melhor apresentação aos estudantes. Até o momento, foram editados nove vídeos, correspondentes aos números 2, 7, 13, 14, 15, 16, 17,18 e 19 do Quadro 2. Os demais estão sendo elaborados pelos alunos autores, em horários disponíveis para atividades extracurriculares.
QuADRO 2

Temas selecionados para confecção dos vídeos

\begin{tabular}{|r|l|}
\hline 1 & Controle de Sinais Vitais \\
\hline 2 & Aferição da Pressão Arterial Não Invasiva \\
\hline 3 & Sonda Nasogástrica \\
\hline 4 & Cateterismo Vesical \\
\hline 5 & Aspiração Orotraqueal \\
\hline 6 & Punção Venosa Periférica \\
\hline 7 & Entubação Orotraqueal \\
\hline 8 & Entubação com Combitube \\
\hline 9 & Entubação com Máscara Laríngea \\
\hline 10 & Oxigenoterapia Não Invasiva \\
\hline 11 & Parto Normal \\
\hline 12 & RCP-DEA-Adulto \\
\hline 13 & Exame da Função Sensitiva \\
\hline 14 & Exame da Força Motora I \\
\hline 15 & Exame da Força Motora II \\
\hline 16 & Exame da Coordenação Motora e Equilíbrio \\
\hline 17 & Exame dos Pares Cranianos \\
\hline 18 & Exame de Reflexos Tendinosos \\
\hline 19 & Exame de Papanicolaou \\
\hline 20 & Exame das Mamas \\
\hline 21 & Propedêutica Respiratória \\
\hline 22 & Propedêutica Cardiovascular \\
\hline 23 & Propedêutica Gastrointestinal \\
\hline
\end{tabular}

Na execução dos vídeos, houve duas etapas: ensaio-gravação e edição. Os tempos destinados a essas etapas e o tempo de filme editado estão descritos na Tabela 1.

TABELA 1

Relação de vídeos e respectivo tempo despendido para ensaio, gravação, edição e e tempo final editado

\begin{tabular}{l|c|c|c}
\hline \multicolumn{1}{c|}{ Vídeos } & $\begin{array}{c}\text { Ensaio e } \\
\text { gravação }\end{array}$ & Edição & $\begin{array}{c}\text { Tempo } \\
\text { editado }\end{array}$ \\
\hline $\begin{array}{l}\text { Aferição da Pressão Arterial } \\
\text { Não Invasiva }\end{array}$ & $1 \mathrm{~h} 30$ & $1 \mathrm{~h} 40$ & $6 \mathrm{~min} 21 \mathrm{~s}$ \\
\hline Entubação Orotraqueal & $1 \mathrm{~h} 30$ & $2 \mathrm{~h} 30$ & $6 \mathrm{~min} 17 \mathrm{~s}$ \\
\hline Exame da Função Sensitiva & $2 \mathrm{~h} 10$ & $1 \mathrm{~h} 30$ & $14 \mathrm{~min} 46 \mathrm{~s}$ \\
\hline Exame da Força Motora I & $1 \mathrm{~h} 20$ & $2 \mathrm{~h} 45$ & $7 \mathrm{~min} 35 \mathrm{~s}$ \\
\hline Exame da Força Motora II & $1 \mathrm{~h} 00$ & $1 \mathrm{~h} 00$ & $2 \mathrm{~min} 29 \mathrm{~s}$ \\
\hline $\begin{array}{l}\text { Exame da Coordenação Motora } \\
\text { e Equilíbrio }\end{array}$ & $2 \mathrm{~h} 00$ & $1 \mathrm{~h} 30$ & $9 \mathrm{~min} 43 \mathrm{~s}$ \\
\hline Exame dos Pares Cranianos & $3 \mathrm{~h} 00$ & $4 \mathrm{~h} 30$ & $23 \mathrm{~min} 44 \mathrm{~s}$ \\
\hline Exame de Reflexos Tendinosos & $2 \mathrm{~h} 00$ & $1 \mathrm{~h} 00$ & $8 \mathrm{~min} 47 \mathrm{~s}$ \\
\hline Exame de Papanicolaou & $1 \mathrm{~h} 00$ & $1 \mathrm{~h} 20$ & $7 \mathrm{~min} 9 \mathrm{~s}$ \\
\hline
\end{tabular}

Utilizando-se os checklists, construiu-se a estrutura passo a passo dos vídeos. 


\section{DISCUSSÃO}

O presente projeto apresenta uma alternativa para melhorar o aprendizado de habilidades e procedimentos médicos por meio da utilização de vídeos educacionais associados à simulação. Trata-se de um projeto piloto, que será seguido por uma pesquisa que avaliará o impacto do uso de tais vídeos no aprendizado dos alunos no curso de Medicina.

Diversos estudos comprovam que o emprego de vídeos pode melhorar o aprendizado de procedimentos médicos. Em um estudo realizado na Universidade de Auckland, na Nova Zelândia, foi apresentado a médicos em treinamento um vídeo sobre cateterismo vesical em homens e mulheres. O grupo de 11 participantes que teve acesso ao vídeo foi comparado a outro, de dez participantes, que não teve acesso ao vídeo. Ambos os grupos receberam treinamento com simulação da sondagem vesical em manequins. Antes do treinamento, foi aplicado um questionário sobre o conhecimento prévio do tema e os níveis de confiança no desempenho da sondagem. Todos os participantes praticaram a sondagem, sendo avaliados pelo mesmo corpo docente. Após a avaliação, os participantes completaram novamente o questionário sobre os níveis de confiança e habilidade. Nos três meses subsequentes, apenas um dos grupos teve acesso ao vídeo, e o outro não recebeu nenhuma intervenção educacional. No final de três meses, os participantes repetiram a avaliação prática de habilidades no laboratório e preencheram novamente o questionário. Observou-se que o grupo que teve acesso aos vídeos obteve maiores índices de competência e autoconfiança, especialmente na sondagem vesical feminina ${ }^{8}$.

No estudo citado, o vídeo foi apresentado após o treinamento, mas os autores do presente estudo acreditam que usar os vídeos no momento do treinamento pode ser ainda mais produtivo, melhorando o desenvolvimento psicomotor e a retenção, no mesmo modelo do Watch then Practice, amplamente utilizado nos treinamentos de ressuscitação cardiopulmonar da American Heart Association, uma das pioneiras no uso deste tipo de técnica9.

Além disso, os vídeos podem ser vistos em dispositivos móveis e divulgados em diversos meios de comunicação, como internet, celulares e redes sociais, ampliando o acesso de médicos e estudantes de Medicina, o que pode estimular o estudo fora da sala de aula e dos laboratórios ${ }^{10-11}$. Apesar do tempo requerido para sua produção, não são necessários altos investimentos, e os vídeos podem ser utilizados repetidamente em diversas situações.

Encontramos algumas barreiras geográficas, que tivemos que transpor. Otimizar o tempo necessário aos ensaios, edições e gravações dos vídeos se tornou um dos nossos principais objetivos, pois a graduação de Medicina é feita em perío- do integral. Assim, comumente, desenvolvíamos nossas atividades após o término das aulas. No ato da gravação, constantemente éramos surpreendidos pela dificuldade técnica, surgindo a necessidade de que alguém gravasse e auxiliasse na montagem das cenas, ocasião em que pedíamos apoio a funcionários ou estudantes, que prontamente nos auxiliavam. Após a gravação, começava o processo de edição, mas não tínhamos no local um computador apto para edição. Por isto, esperávamos os fins de semana, para concretizar a edição na residência de um dos idealizadores do projeto, situada no interior de São Paulo.

Hoje, quem assiste aos vídeos tem a percepção de que dispusemos de excelente infraestrutura no laboratório de simulação - todos os materiais, anatomia e, principalmente, o procedimento. Pudemos escolher vários ambientes e bonecos para aperfeiçoar a didática com os vídeos e associá-los à apresentação, o que se refletiu no esclarecimento de dúvidas no estudo individualizado do aluno na ausência do professor.

É importante ressaltar a grande contribuição dos estudantes no desenvolvimento e aprimoramento do processo educacional. A visão das novas gerações, afeitas à tecnologia, permite criativas soluções que melhoram a aprendizagem. Além disso, o envolvimento dos alunos nos processos pedagógicos os motiva ainda mais para o estudo e possibilita que tomem as rédeas de seu aprendizado, deixando de ser espectadores para se tornarem protagonistas no cenário da educação médica.

\section{CONCLUSÃO}

O presente projeto oferece uma nova abordagem pedagógica para melhorar as competências dos estudantes de Medicina e sua autoconfiança na realização de procedimentos, por meio de vídeos educativos elaborados pelos alunos e dirigidos a este mesmo público. Estes materiais podem ser utilizados em aulas pelos professores e também disponibilizados para estudo individualizado, uma vez que facilitam o aprendizado e a memorização do conteúdo.

Partindo desta iniciativa, os alunos evidenciam que a responsabilidade do ensino não tem que proceder apenas do docente e que a visão dos estudantes sobre novas tecnologias pode contribuir grandemente para o aperfeiçoamento do processo educacional, de forma a fortalecer o ensino médico.

\section{REFERÊNCIAS}

1. Grant DJ, Marriage SC. Training using medical simulation. Arch. Dis. Child. 2011.

2. Ziv A, Wolpe PR, Small SD, Glick S. Simulation-based medical education: an ethical imperative. Simul Healthc. 2006; 1(4):252-6. 
3. Mayer RE. Multimedia Learning. Cambridge, UK: Cambridge University Press; 2001.

4. Anon. iPods in bedside medical education: improving care in developing countries. Apple Inc. 2010.

5. Maag M. Podcasting and MP3 players: emerging education technologies. Comput Inform Nurs. 2006;24(1):9-13.

6. Osterweil N. Medical students take iPod sounds to heart. Medpage Today. 2007.

7. Jelesiewicz E. iPods help docs improve stethoscope skills. Temple Time Online Edition. 2007.

8. Hansen M, Oosthuizen G, Windsor J, Doherty I, Greig S, McHardy K et al. Enhancement of Medical Interns' Levels of Clinical Skills Competence and Self-Confidence Levels via Video iPods: Pilot Randomized Controlled Trial. J Med Internet Res. 2011;13(1):e29.

9. American Heart Association Guidelines 2005 for Cardiopulmonary Ressuscitation and Emergency Cardiovascular Care. Circulation. 2005; 112: 4-19.

10. Santoro E, Caldarola P, Villella A. [Using Web 2.0 technologies and social media for the cardiologist's education and update]. G Ital Cardiol (Rome). 2011;12(3):174-81.

11. Oblinger DG, Oblinger JL. Educating the net generation. Educause. 2005.

\section{CONTRIBUIÇÃO DOS AUTORES}

Ana Paula Quilici - Orientadora do projeto e diretora do centro de simulação ao qual foram gravados os vídeos.

Allan Danek e Felipe Teles de Arruda - Programação das atividades, busca bibliográfica e literária dos temas abordados e produção dos vídeos.

Karen Cristine Abrão - Médica orientadora dos procedimentos e semiologia. Assistência técnico-científico para consolidação do projeto.

\section{CONFLITO DE INTERESSES}

Declarou não haver.

\section{ENDEREÇO PARA CORRESPONDÊNCIA}

Felipe Teles de Arruda

Rua Professor Edson dos Santos Nunes, 364.

Jardim Cruzeiro — Mairinque

São Paulo — SP

CEP: $18120-00$

Email: felipe_telles_pipe@hotmail.com 